\title{
Geographical distribution of the association between El Niño South Oscillation and dengue fever in the Americas: a continental analysis using geographical information system-based techniques
}

\author{
Marcos C. Ferreira \\ Campinas State University - UNICAMP, Geosciences Institute, Department of Geography, Campinas, São \\ Paulo, Brazil
}

\begin{abstract}
El Niño South Oscillation (ENSO) is one climatic phenomenon related to the inter-annual variability of global meteorological patterns influencing sea surface temperature and rainfall variability. It influences human health indirectly through extreme temperature and moisture conditions that may accelerate the spread of some vector-borne viral diseases, like dengue fever (DF). This work examines the spatial distribution of association between ENSO and DF in the countries of the Americas during 1995-2004, which includes the 1997-1998 El Niño, one of the most important climatic events of $20^{\text {th }}$ century. Data regarding the South Oscillation index (SOI), indicating El Niño-La Niña activity, were obtained from Australian Bureau of Meteorology. The annual DF incidence $\left(A I_{y}\right)$ by country was computed using Pan-American Health Association data. SOI and $A I_{y}$ values were standardised as deviations from the mean and plotted in bars-line graphics. The regression coefficient values between $\mathrm{SOI}$ and $A I_{y}\left(r_{S O I, A I}\right)$ were calculated and spatially interpolated by an inverse distance weighted algorithm. The results indicate that among the five years registering high number of cases $(1998,2002,2001,2003$ and 1997), four had El Niño activity. In the southern hemisphere, the annual spatial weighted mean centre of epidemics moved southward, from $6^{\circ} 31^{\prime} \mathrm{S}$ in 1995 to $21^{\circ} 12^{\prime} \mathrm{S}$ in 1999 and the $r_{S O I, A I}$ values were negative in Cuba, Belize, Guyana and Costa Rica, indicating a synchrony between higher DF incidence rates and a higher El Niño activity. The $r_{S O I, A I}$ map allows visualisation of a graded surface with higher values of ENSO-DF associations for Mexico, Central America, northern Caribbean islands and the extreme north-northwest of South America.
\end{abstract}

Keywords: dengue fever, geographical information system, climatic variability, Americas, El Niño, El Niño South Oscillation.

\section{Introduction}

Social and environmental phenomena caused by variability of the climate have received increased attention in the last decade. Scientific discussions, based on $20^{\text {th }}$ century data supporting the idea that there is a tendency towards global warming, continue to contribute to the diffusion of the climate change theme through global media and governments. The El Niño South Oscillation (ENSO) is one of these climatic phenomena related to the inter-annual variability of global meteorological patterns. El Niño events are characterised by a relative increase in the temperature of the surface layers of the tropical eastern Pacific Ocean,

Corresponding author: Marcos César Ferreira

Campinas State University - UNICAMP

Geosciences Institute, Department of Geography

Brazil R. Joao Pandia Calogeras 51, CEP 13083-870

Campinas, São Paulo, Brazil

Tel. +55 19 3521-4570; Fax +55 19 3289-1562

E-mail: macferre@uol.com.br while La Niña events portray the opposite, i.e. a cooling of the ocean surface water. These events typically occur every 2-7 years and develop in association with large-scale oscillations in atmospheric pressure over the tropical Indian and Pacific oceans (Stewart-Ibarra and Lowe, 2013). The action centre of ENSO, located in the Equatorial Pacific, influences seasonal wind dynamics, ocean currents, sea surface temperatures and rainfall fluctuations (Nicholls, 1993). These fluctuations are related to the atypical dynamics of the oceanic currents that mainly occur along the South American west coast in the month of December. Under normal oceanic temperature conditions, the Humboldt cold current reaches the South American west coast and maintains ocean waters at a relatively low temperature resulting in predominately cloudy weather and low rainfall indices in the Andean coastal countries (Kiska, 2000). During El Niño events, however, the speed of westward warm winds falls along the Andean Pacific coast diminishes the intensity of the Humboldt cold current resulting in rising oceanic temperatures, which affects atmospheric patterns and produces tropical rainfalls. These effects are not restricted to this 
region but causes increased rainfall also in south-eastern United States of America (USA) and weak summers in the southern and south-eastern regions of Brazil. Particularly intense events were registered between 1984 and 1995, e.g. the ENSO of 1991 was unusually long and in 1997 the relative sea surface temperature rose $4{ }^{\circ} \mathrm{C}$ above the normal of around $21^{\circ} \mathrm{C}$ (Epstein and Sharp, 1993; Manabe and Stoufer, 1993; Kiska, 2000). In some places, the water temperature peak at $>5{ }^{\circ} \mathrm{C}$ above normal temperatures (NASA, 1999).

The environmental phenomena emerging from the ENSO also influences human health. Although people can adapt to different climates, extreme temperature and moisture conditions may accelerate the spread of diseases transmitted by arthropod vectors (Nicholls, 1993). One of the most important recent problems is the increase of dengue fever (DF), which is a vector-borne, viral disease. Many insect vectors reproduce best in warm and humid climates, conditions that contribute to the spatial dispersion of tropical epidemics, such as malaria, yellow fever and DF, among others. Research has demonstrated that there is an association between ENSO and vectorborne viral diseases in tropical and subtropical regions (Curto de Casas and Carcavallo, 1995; Cazales et al., 2005; Chadee et al., 2007). For example, the ENSO events have been shown to be related to fluctuations in the number of malaria cases in the area of Sucre, Venezuela (Delgado-Petrucelli et al., 2012). In periods of climatic changes, these vectors may also be found in temperate regions of the world. Recently, vectors of Aedes aegypti (Lutz) and Ae. albopictus (Skuse) were found in abundance in the lower Rio Grande Valley, Texas, USA (Vitek et al., 2014). Extreme ENSO-associated events, like storms and tornados, have also been shown to be related to the number of DF cases, e.g. in Honduras (Moreno, 2006) and the DF incidence in the Caribbean countries is also higher during El Niño periods (Chen and Taylor, 2002; Amarakoon et al., 2008). The rising sea temperatures during ENSO years are associated with higher numbers of DF cases in cities located along the coast of the Gulf of Mexico (Hurtado-Diáz et al., 2007) as well as in the cities of Suriname, French Guiana and Colombia (Gagnon et al., 2001).

Four different dengue viruses (DEN1-4) with a $65 \%$ genetic similarity cause DF that can show various symptoms resulting in different specific clinical syndromes. The disease was introduced into Central America and the Caribbean from Asia by travellers in three phases starting with the DEN-1 serotype in 1977, followed by DEN-2 and DEN-3 in 1981, while the DEN-4 that can cause haemorrhagic DF did not arrive until 1994 (Wilder-Smith and Gubler, 2008).

The influence of El Niño on tropical vector-borne diseases has been studied using correlation techniques based on the South Oscillation index (SOI). The SOI indicates the intensity of ENSO events in the Pacific Ocean and is calculated by the following equation (NOAA, 2014):

$$
S O I=\frac{\left(\frac{a T_{S L P}-m T_{S L P}}{s d T_{S L P}}\right)-\left(\frac{a D_{S L P}-m D_{S L P}}{s d D_{S L P}}\right)}{\sqrt{\frac{\left(z_{T}-z_{D}\right)^{2}}{N}}}
$$

(equation 1)

where $a T_{S L P}$ and $a D_{S L P}$ represent the actual sea level pressure (SLP) at Tahiti and Darwin, respectively, $m T_{S L P}$ and $m D_{S L P}$ the mean SLP, $s d T_{S L P}$ and $s d D_{S L P}$ the SLP standard deviation and $z_{T}$ and $z_{D}$ the standardised SLP at these two places. $N$ is the number of months.

The SOI has been used as a reference to the climatic variability studies related to the El Niño phenomena and it has been shown that DF is positively correlated with the SOI in many South Pacific countries (Hales et al., 1999). A study carried out by Amarakoon et al. (2008) in Caribbean countries shows that the SOI has a positive cross-correlation coefficient $(r)$ with the number of DF cases in Trinidad and Tobago $(r=0.53)$, Barbados $(r=0.47)$ and Mexico $(r=0.51)$ with a 4month lag time. The $r$ coefficient evaluates the synchronism between DF and SOI time series and shows also the number of months, in which a positive association between both series occurs. A forecast model for estimating the potential impact of ENSO on DF transmission in Queensland, Australia has been developed by Hu et al. (2010). The results show that a SOI decrease is significantly associated with an increase in the number of monthly DF cases. Most of the studies assessing the relationship between ENSO and dengue epidemics are conducted at the country level, so there is a lack of information evaluating this relationship at the continental or global scale. The goal of this study was to examine and map the association between ENSO fluctuations and the spatial distribution of DF in the Americas (Fig. 1) using a geographical information system (GIS) approach. The time period of 1995-2004 was selected because it includes the 1997-1998 El Niño, one of the most discussed climatic event of $20^{\text {th }}$ century (Changnon, 2000). 


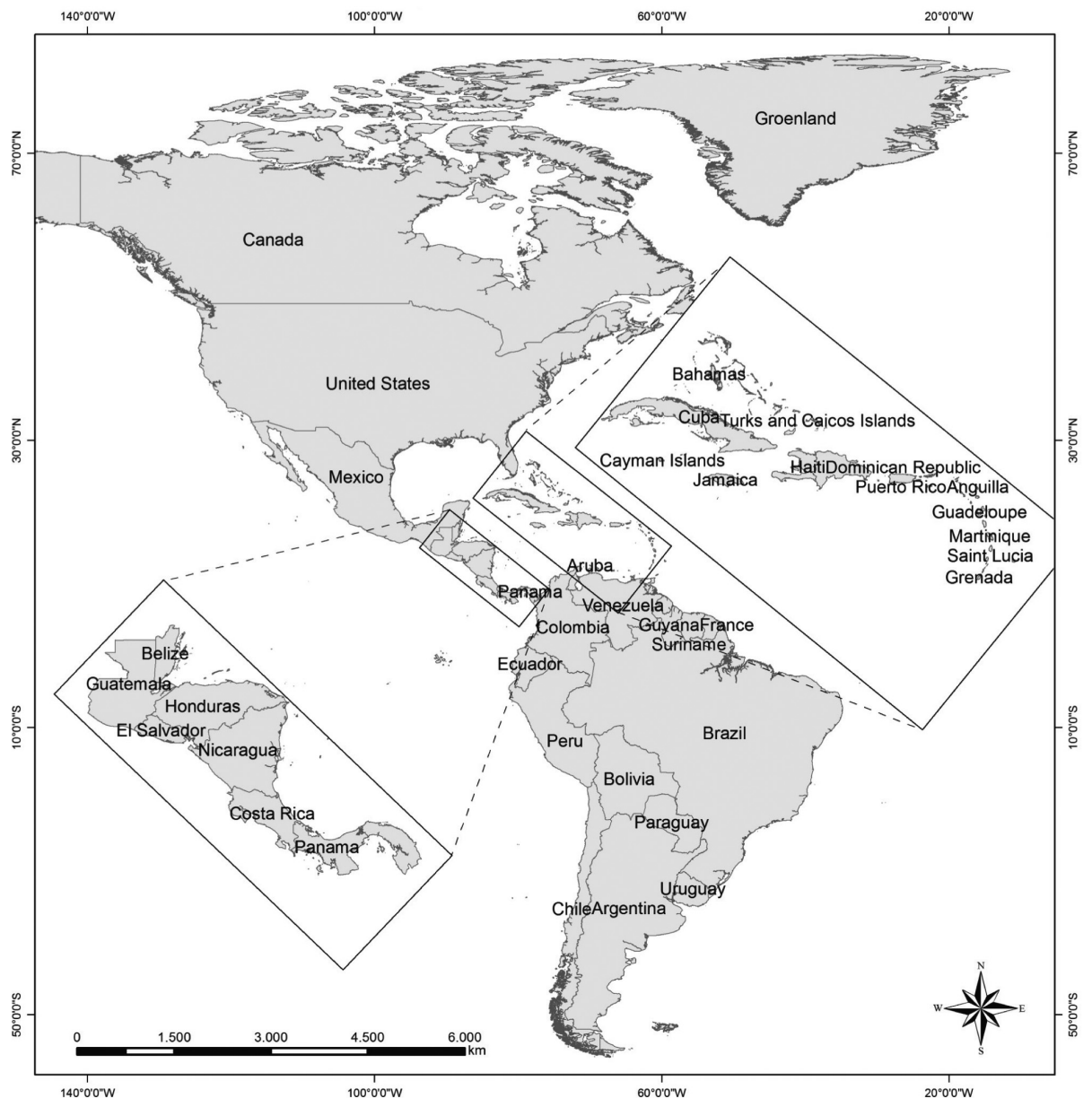

Fig. 1. Map of the North, Central and South American countries.

\section{Material and methods}

Annual data covering DF disease and the total population in all countries in the Americas with autochthonous cases for the period 1995-2004 were obtained from Pan-American Health Association (PAHO, 2007). Using the formula in equation 2, these original data were transformed into figures giving the annual DF incidence per 10,000 inhabitants by country $\left(A I_{y}\right)$ :

$$
A I_{y}=\left(\frac{T_{y}}{P_{y}}\right) \times 10^{4}
$$

(equation 2)

where $T_{y}$ is the total number of autochthonous DF cases reported in year $y$ with $P_{y}$ being the total population of that country in that year. The $A I_{y}$ values were mapped using ArcGIS version 10 (ESRI, 2011) and a vector shapefile database containing all borders of the countries in the Americas. Annual anomalies of $A I_{y}$ in relation to the 1995-2004 entire time series were computed using equation 3 . Table 1 presents the monthly
SOI values from 1995 to 2004 with their means and standard deviations (SD) that were obtained from the website of the Australian Bureau of Meteorology (2007) (http://www.bom.gov.au/climate/current/soihtm1.shtml).

The SOI data are reported monthly, while the DF data are available annually. We therefore used the SOI annual mean values $(\overline{S O I})$ rather than the original SOI monthly values $\left(S O I_{i}\right)$, as described by equation 3 :

$$
(\overline{S O I})=\frac{\sum_{i=1}^{12} S O I_{i}}{12}
$$

(equation 3)

The more negative $\overline{X_{S O I}}$ value, the more intensive the El Niño in that year and the more positive this variable, the more intensive the La Niña. After, both $\overline{X_{S O I}}$ and $A I_{y}$ values were standardised as $z$ values of deviations (equations 4 and 5):

$$
z_{A I_{i}}=\frac{A I_{i}-\overline{X_{A I_{i}}}}{\sigma_{A I_{i}}}
$$

(equation 4) 
Table 1. Monthly values of the Southern Oscillation index (SOI) from 1995 to 2004.

\begin{tabular}{|c|c|c|c|c|c|c|c|c|c|c|c|c|c|c|}
\hline Year & Jan & Feb & Mar & Apr & May & Jun & Jul & Aug & Sep & Oct & Nov & Dec & Mean & SD \\
\hline 1995 & -4.0 & -2.7 & 3.5 & -16.2 & -9.0 & -1.5 & 4.2 & 0.8 & 3.2 & -1.3 & 1.3 & -5.5 & -2.3 & 5.9 \\
\hline 1996 & 8.4 & 1.1 & 6.2 & 7.8 & 1.3 & 13.9 & 6.8 & 4.6 & 6.9 & 4.2 & -0.1 & 7.2 & 5.7 & 3.8 \\
\hline 1997 & 4.1 & 13.3 & -8.5 & -16.2 & 22.4 & 24.1 & -9.5 & 19.8 & 14.8 & -17.8 & 15.2 & -9.1 & -11.7 & 10.9 \\
\hline 1998 & -23.5 & 19.2 & -28.5 & -24.4 & 0.5 & 9.9 & 14.6 & 9.8 & 11.1 & 10.9 & 12.5 & 13.3 & -1.9 & 17.3 \\
\hline 1999 & 15.6 & 8.6 & 8.9 & 18.5 & 1.3 & 1.0 & 4.8 & 2.1 & -0.4 & 9.1 & 13.1 & 12.8 & 8.0 & 6.2 \\
\hline 2000 & 5.1 & 12.9 & 9.4 & 16.8 & 3.6 & -5.5 & -3.7 & 5.3 & 9.9 & 9.7 & 22.4 & 7.7 & 7.8 & 7.8 \\
\hline 2001 & 8.9 & 11.9 & 6.7 & 0.3 & -9.0 & 1.8 & -3.0 & -8.9 & 1.4 & -1.9 & 7.2 & -9.1 & 0.5 & 7.2 \\
\hline 2002 & 2.7 & 7.7 & -5.2 & -3.8 & 14.5 & -6.3 & -7.6 & 14.6 & -7.6 & -7.4 & -6.0 & -10.6 & -6.1 & 6.4 \\
\hline 2003 & -2.0 & -7.4 & -6.8 & -5.5 & -7.4 & -12.0 & 2.9 & -1.8 & -2.2 & -1.9 & -3.4 & 9.8 & -3.1 & 5.6 \\
\hline 2004 & -11.6 & 8.6 & 0.2 & -15.4 & 13.1 & 14.4 & -6.9 & -7.6 & -2.8 & -3.7 & -9.3 & -8.0 & -4.8 & 8.7 \\
\hline
\end{tabular}

Information collected at http://www.bom.gov.au/climate/current/soihtm1.shtml.

$$
z_{\mathrm{SOI}_{i}}=\frac{\overline{S O I}_{i}-\overline{X_{\mathrm{SOI}_{i}}}}{\sigma_{\mathrm{SOI}_{i}}}
$$

(equation 5)

where, $\overline{X_{S O I}}$ represents the SOI mean value and $\overline{X_{A I_{i}}}$ the $A I$ mean values, wile $\sigma_{S O I_{i}}$ and $\sigma_{A I_{i}}$ are the $\mathrm{SD}$ for these values, respectively, during the 1995-2004 period.

We estimated the spatial weighted mean centre of $A I_{y}$ in the Americas $\left(W A I_{y}\right.$ ) for each year using equations 6 and 7 adapted from Cliff and Haggett (1998):

$$
\begin{gathered}
\operatorname{long}_{w}=\frac{\sum_{i=1}^{n} A I_{i} \text { long }_{i}}{\sum_{i=1}^{n} A I_{i}} \\
\text { lat }_{w}=\frac{\sum_{i=1}^{n} A I_{i} \text { lat }_{i}}{\sum_{i=1}^{n} A I_{i}}
\end{gathered}
$$

(equation 6)

(equation 7)

where $l a t_{w}$ and $\operatorname{long}_{w}$ are the latitude and the longitude of the weighted mean centre and $A I_{i}$ the annual DF incidence at longitude $i\left(\right.$ long $\left._{i}\right)$ and latitude $i\left(\right.$ lat $\left._{i}\right)$.

To assess the continental ENSO influence on the DF incidence, we calculated the $r$ coefficients between $\overline{X_{\mathrm{SOI}}}$ and $A I_{y}$ values for all countries that had autochthones cases registered. These $r$-values were added as a new column to the shapefile attribute table. Subsequently, the $r$-values were transformed into a point shapefile with each point positioned in the centroid of the country polygons. In the spatial analyst module of ArcGIS version 10 , the $r$-values points were interpolated using the inverse distance weighted (IDW) algorithm, based on a $10 \mathrm{x} 10 \mathrm{~km}$ grid in the 12 nearest points. This algorithm calculates the $r$-values for all such grid cells using the mean distance to the nearest points with known $r$-values as spatial weights. Finally, an $r$-value isoline map was produced from interpolated values grid using the smooth spline algorithm.

\section{Results}

A total of 4,863,598 cases of DF were reported in all the Americas in the 1995-2004 time series. Fig. 2 shows the hierarchy of the years according to the number of autochthonous DF cases reported each year; and the relative predominance of El Niño or La Niña event for that year. The maximum numbers of DF cases in the Americas were reported in 1998 and 2002 (Fig. 3). In those years, the proportion of infected countries was higher too. In 1996 and 1997, the number of DF cases was small and restricted to just a few countries. In 1999 and 2000, the number of DF cases was also small but reached a greater number of countries, while both the total number of DF cases and the proportion of infected countries were high in 2002.

The results indicate that El Niño activity has occurred in four out of the five years, in which a higher than normal number of DF cases were registered (1997, 1998, 2002 and 2003). From 1995 to 2004, a slight upward trend in annual DF incidence values for the Americas was noted (Fig. 3). The annual DF incidence curve oscillated around three peaks: 1995 $\left(A I_{y}=10.72\right), \quad 1998 \quad\left(A I_{y}=7.64\right)$ and 2001 $\left(A I_{y}=12.36\right)$.

$\mathrm{DF}$ annual incidence and the mean annual incidence from 1995-2004 values for all countries that had registered at least one DF case in the time series are shown in Table 2, and the standardised values in Table 3. Fig. 4 shows the DF annual incidence anomalies 


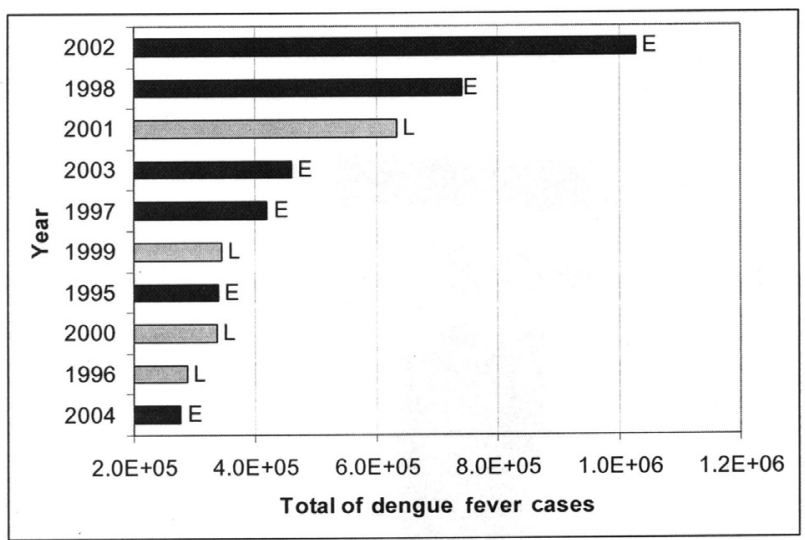

Fig. 2. Time series sorted according to the total, annual number of reported DF cases and the correspondence of these numbers with ENSO. E = El Niño events; L = La Niña events.

maps based on $z$ values computed from 1995-2004 time series. The differences between positive anomalies (PA) and negative anomalies (NA) are clearly seen. In 1995, the PA with respect to DF annual incidence was higher in Mexico, Honduras, Nicaragua and Panama as well as in some countries located in the northern part of South America (Equator, Colombia and Venezuela). On the other hand, the NA occurred in most of southern South American countries that year. In 1996, there were NA in almost all countries except in Peru, Suriname and Mexico, where the anomalies were near zero. The 1997 map shows a distribution of anomalies almost similar to the 1995 map, i.e. PA in Mexico and Central America and NA in most of the South American countries. The 1998 map shows a strong predominance of PA in Brazil, Colombia Venezuela, Suriname and Argentina and Mexico, while NA was observed mainly in Andean region (Bolivia, Peru, Equator and Chile). 1998 was also the year when DF occurred for the first time in Argentina. The NA values were predominant in 1999 and 2000 maps with exception of Paraguay (high PA value in 1999); Panama, Nicaragua and Honduras (low PA values in 1999); and Argentina, Suriname, Guatemala and Belize (high PA in 2000).

An increasing PA was noted in the South America in 2001 and 2002, mainly in the latter year and in Brazil, Colombia, Equator, Suriname, Guyana and Chile. In the two last years of time series, 2003 and 2004, PA still remained but with less strength. It is possible to see PA in the Andean countries (Bolivia, Peru and Equator) as well as in Argentina and Suriname in 2003 and 2004 maps. In the 2000-2004 maps, most of the Central American countries, including Mexico, had no longer PA values.

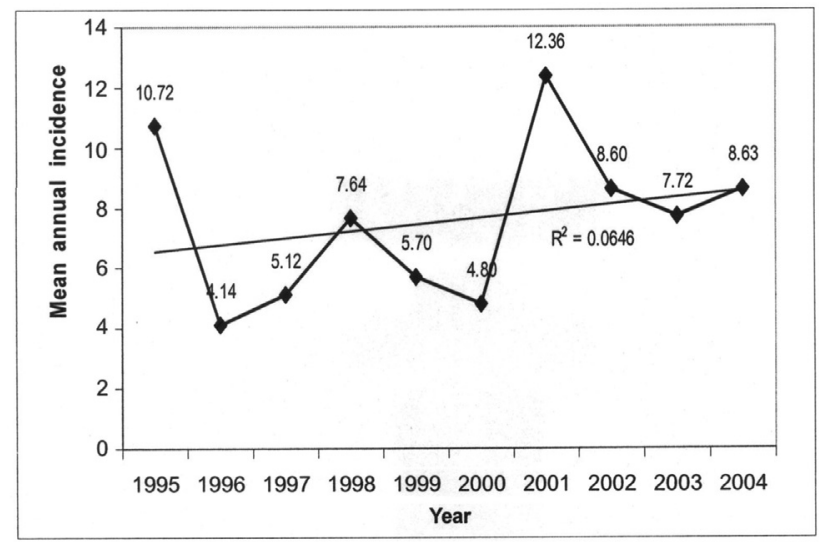

Fig. 3. Evolution of the annual mean incidence of DF in the Americas from 1995 to 2004.

Fig. 5 shows the standardised annual DF incidence from selected countries of the Americas and SOI anomalies. It was noted that the association between SOI and DF varied positively and negatively from one country to other. In selected countries (Cuba, Belize, Guyana and Costa Rica) negative correlation coefficient values between DF annual incidence and SOI $(\mathrm{P}=0.025)$ were noted. In those countries, there was a relative synchrony between positive deviations of the $\mathrm{DF}$ annual incidence and negative deviations of SOI values.

In 1996 and 1997, the DF annual incidence and SOI deviations oscillated in an inverse way, passing from low DF and high SOI deviations in 1996 (La Niña) to high a DF annual incidence and a low SOI deviation in 1997 (El Niño). In 1999 and 2000 (two consecutive La Niña years), negative DF annual incidence deviations were associated with positive SOI deviations. From 2002 to 2004 (El Niño event years), this relationship was only maintained in Costa Rica. These associations are better seen in the two stronger El Niño years 1997 and 2002 (Fig. 5). In these years, the two higher positive deviations of the DF annual incidence were seen linked to the two lower SOI negative deviations. The right part of Fig. 5 shows the association between SOI and DF graphs from Paraguay, Suriname, Bermuda and Nicaragua. These nations presented relatively positive correlation coefficient values between the annual DF incidence and SOI $(\mathrm{P}=0.10$ and 0.025 , respectively). In Paraguay, Bermuda and Nicaragua, the higher DF incidence positive deviation occurred in 1999 (the strongest La Niña event year in the series) and was synchronised with a positive SOI deviation. The graph from Suriname shows a direct link between the lower negative SOI and the lower DF incidence deviation, 
Table 2. The annual DF incidence per 10,000 inhabitants $\left(A I_{y}\right)$ and the mean annual incidence in 1995-2004 period $\left(\overline{X_{A I}}\right)$ computed for the countries of the Americas.

\begin{tabular}{|c|c|c|c|c|c|c|c|c|c|c|c|}
\hline \multirow{2}{*}{ Country } & \multicolumn{10}{|c|}{$A I_{y}$ (autochthonous DF cases by 10,000 inhabitants) } & \multirow{2}{*}{$\overline{X_{A I_{i}}}$} \\
\hline & 1995 & 1996 & 1997 & 1998 & 1999 & 2000 & 2001 & 2002 & 2003 & 2004 & \\
\hline Anguilla & 0.00 & 0.00 & 0.00 & 0.00 & 0.00 & 0.00 & 20.83 & 4.17 & 1.54 & 0.00 & 2.65 \\
\hline Antigua & 8.75 & 1.88 & 1.08 & 0.62 & 0.30 & 1.21 & 2.99 & 0.75 & 0.15 & 0.00 & 1.77 \\
\hline Argentina & 0.00 & 0.00 & 0.00 & 0.23 & 0.00 & 0.46 & 0.00 & 0.06 & 0.04 & 0.86 & 0.16 \\
\hline Aruba & 5.44 & 1.47 & 0.00 & 0.00 & 18.84 & 10.86 & 0.00 & 3.57 & 0.00 & 30.14 & 7.03 \\
\hline Bahamas & 0.04 & 0.00 & 0.00 & 11.47 & 0.00 & 0.00 & 0.00 & 0.00 & 5.73 & 0.03 & 1.78 \\
\hline Barbados & 37.25 & 4.94 & 7.54 & 32.15 & 26.26 & 27.97 & 39.06 & 27.61 & 20.78 & 12.97 & 23.66 \\
\hline Belize & 5.00 & 0.00 & 6.27 & 0.35 & 0.13 & 0.17 & 0.12 & 1.62 & 0.00 & 0.08 & 1.37 \\
\hline Bermuda & 0.00 & 0.00 & 0.00 & 0.00 & 0.48 & 0.00 & 0.00 & 0.00 & 0.00 & 0.00 & 0.05 \\
\hline Bolivia & 0.01 & 0.07 & 0.69 & 0.06 & 0.05 & 0.09 & 0.21 & 1.03 & 4.72 & 8.20 & 1.51 \\
\hline Brazil & 7.74 & 10.73 & 15.28 & 31.72 & 11.92 & 13.28 & 23.42 & 43.64 & 18.85 & 6.14 & 18.27 \\
\hline Cayman & 0.31 & 0.00 & 0.00 & 0.56 & 0.27 & 0.00 & 0.00 & 0.24 & 0.24 & 0.00 & 0.16 \\
\hline Chile & 0.00 & 0.00 & 0.00 & 0.00 & 0.00 & 0.00 & 0.00 & 0.40 & 0.00 & 0.00 & 0.04 \\
\hline Colombia & 13.25 & 8.44 & 6.08 & 15.52 & 5.18 & 5.40 & 12.94 & 17.69 & 0.00 & 6.13 & 9.06 \\
\hline Costa Rica & 14.77 & 6.47 & 39.03 & 7.01 & 15.70 & 12.49 & 23.01 & 29.90 & 47.10 & 22.12 & 21.76 \\
\hline Cuba & 0.00 & 0.00 & 2.74 & 0.00 & 0.00 & 0.12 & 1.17 & 2.69 & 0.00 & 0.00 & 0.67 \\
\hline Dominican Republic & 0.32 & 0.11 & 0.77 & 3.80 & 1.34 & 4.19 & 4.28 & 3.75 & 7.13 & 2.82 & 2.85 \\
\hline Dominica & 40.14 & 0.41 & 2.19 & 3.97 & 0.14 & 2.08 & 0.70 & 0.00 & 0.00 & 0.58 & 5.02 \\
\hline El Salvador & 17.04 & 1.36 & 0.73 & 2.80 & 1.02 & 5.17 & 1.71 & 28.07 & 11.19 & 19.73 & 4.54 \\
\hline Equator & 8.47 & 0.68 & 0.36 & 1.41 & 0.52 & 2.64 & 0.88 & 14.45 & 5.79 & 10.23 & 8.88 \\
\hline French Guiana & 64.46 & 25.45 & 57.11 & 34.68 & 5.53 & 11.34 & 167.46 & 16.09 & 122.36 & 171.97 & 67.65 \\
\hline Granada & 8.13 & 0.67 & 2.44 & 0.44 & 9.55 & 3.03 & 1.35 & 9.44 & 0.34 & 0.79 & 3.62 \\
\hline Guadalupe & 3.81 & 4.50 & 0.00 & 0.00 & 0.96 & 1.40 & 0.00 & 2.12 & 11.25 & 11.89 & 3.59 \\
\hline Guatemala & 3.99 & 3.61 & 5.16 & 4.36 & 3.32 & 7.84 & 3.95 & 6.49 & 5.63 & 5.17 & 4.95 \\
\hline Guyana & 0.00 & 0.00 & 2.17 & 0.00 & 0.00 & 0.26 & 0.80 & 2.70 & 0.44 & 0.00 & 0.64 \\
\hline Haiti & 0.00 & 0.00 & 0.00 & 0.00 & 0.00 & 0.00 & 0.00 & 1.42 & 0.00 & 0.00 & 0.14 \\
\hline Honduras & 49.02 & 8.73 & 19.97 & 36.39 & 28.47 & 21.47 & 13.79 & 47.89 & 24.02 & 28.34 & 27.81 \\
\hline Jamaica & 7.58 & 0.18 & 0.06 & 6.09 & 0.09 & 0.10 & 0.15 & 0.34 & 0.20 & 0.03 & 1.48 \\
\hline Martinique & 13.84 & 11.38 & 6.18 & 1.15 & 6.98 & 4.43 & 115.23 & 10.05 & 20.18 & 25.03 & 21.45 \\
\hline Mexico & 3.95 & 3.88 & 5.60 & 2.43 & 1.51 & 0.23 & 0.61 & 0.96 & 0.48 & 0.78 & 2.04 \\
\hline Montserrat & 68.18 & 2.73 & 0.00 & 0.00 & 0.00 & 15.00 & 1.25 & 1.25 & 1.11 & 0.00 & 8.95 \\
\hline Nicaragua & 43.02 & 6.10 & 6.69 & 28.52 & 22.94 & 14.75 & 4.16 & 4.48 & 5.31 & 1.93 & 13.79 \\
\hline Panama & 11.55 & 2.98 & 9.49 & 9.88 & 9.62 & 1.07 & 5.14 & 2.32 & 0.99 & 1.30 & 5.44 \\
\hline Paraguay & 0.00 & 0.00 & 0.00 & 2.24 & 45.49 & 0.07 & 3.34 & 0.24 & 0.28 & 0.00 & 5.17 \\
\hline Peru & 1.15 & 2.64 & 0.55 & 0.39 & 0.22 & 2.11 & 8.85 & 3.32 & 1.34 & 3.55 & 2.41 \\
\hline Puerto Rico & 17.68 & 12.49 & 18.52 & 45.57 & 13.11 & 6.34 & 13.53 & 7.69 & 9.55 & 8.36 & 15.29 \\
\hline San Vicente & 19.82 & 16.67 & 0.26 & 7.65 & 0.70 & 0.43 & 0.26 & 10.68 & 0.25 & 0.34 & 5.71 \\
\hline St. Kitts & 0.00 & 0.00 & 0.00 & 0.00 & 0.00 & 0.00 & 22.82 & 5.13 & 0.51 & 1.03 & 2.95 \\
\hline St. Lucia & 3.51 & 4.36 & 0.79 & 0.07 & 0.20 & 0.00 & 18.72 & 2.80 & 0.32 & 0.69 & 3.15 \\
\hline Suriname & 8.29 & 16.20 & 2.13 & 27.02 & 16.16 & 24.72 & 17.39 & 25.03 & 6.42 & 8.41 & 15.18 \\
\hline Trinidad and Tobago & 2.48 & 31.46 & 6.17 & 24.45 & 9.88 & 16.08 & 17.41 & 48.31 & 17.65 & 4.20 & 17.81 \\
\hline Turks and Caicos Islands & 0.00 & 0.00 & 0.00 & 0.00 & 0.00 & 0.00 & 0.00 & 1.05 & 0.53 & 0.00 & 0.16 \\
\hline Venezuela & 14.61 & 4.07 & 14.65 & 16.00 & 11.15 & 8.64 & 33.43 & 14.86 & 10.46 & 11.68 & 13.96 \\
\hline
\end{tabular}


Table 3. The standardised DF annual incidence values in 1995-2004 period $\left(Z_{A I y}\right)$ for the countries of the Americas.

\begin{tabular}{|c|c|c|c|c|c|c|c|c|c|c|}
\hline \multirow{2}{*}{ Country } & \multicolumn{10}{|c|}{$Z_{A I}$} \\
\hline & 1995 & 1996 & 1997 & 1998 & 1999 & 2000 & 2001 & 2002 & 2003 & 2004 \\
\hline Anguilla & -0.433 & -0.433 & -0.433 & 0.433 & -0.433 & -0.433 & 2.610 & 0.176 & -0.189 & -0.433 \\
\hline Antigua & 2.511 & -0.045 & -0.336 & 0.510 & -0.626 & -0.278 & 0.420 & -0.452 & -0.684 & -0.742 \\
\hline Argentina & -0.720 & -0.720 & -0.720 & 0.048 & -0.718 & 0.669 & -0.711 & -0.546 & -0.610 & 1.964 \\
\hline Aruba & -0.170 & -0.546 & -0.686 & 0.686 & 1.126 & 0.373 & -0.686 & -0.337 & -0.686 & 2.296 \\
\hline Bahamas & -0.443 & -0.451 & -0.451 & 2.477 & -0.451 & -0.451 & -0.451 & -0.451 & 1.117 & -0.443 \\
\hline Barbados & 1.105 & -1.586 & -1.367 & 0.711 & 0.214 & 0.367 & 1.318 & 0.354 & -0.228 & -0.890 \\
\hline Belize & 1.487 & -0.604 & 2.152 & 0.448 & -0.545 & -0.526 & -0.545 & 0.197 & -0.604 & -0.565 \\
\hline Bermuda & -0.316 & -0.316 & -0.316 & 0.316 & 2.846 & -0.316 & -0.316 & -0.316 & -0.316 & -0.316 \\
\hline Bolivia & -0.538 & -0.520 & -0.323 & 0.521 & -0.523 & -0.511 & -0.470 & -0.181 & 1.143 & 2.443 \\
\hline Brazil & -0.919 & -0.676 & -0.302 & 1.040 & -0.540 & -0.412 & 0.457 & 2.211 & 0.117 & -0.976 \\
\hline Cayman & 0.572 & -0.858 & -0.858 & 2.002 & 0.572 & -0.858 & -0.858 & 0.572 & 0.572 & -0.858 \\
\hline Chile & -0.316 & -0.316 & -0.316 & 0.316 & -0.316 & -0.316 & -0.316 & 2.846 & -0.316 & -0.316 \\
\hline Colombia & 0.577 & -0.190 & -0.570 & 1.097 & -0.691 & -0.636 & 0.765 & 1.689 & -1.611 & -0.431 \\
\hline Costa Rica & -0.623 & -1.133 & 1.025 & 1.075 & -0.459 & -0.664 & 0.118 & 0.661 & 2.000 & 0.149 \\
\hline Cuba & -0.592 & -0.592 & 1.798 & 0.592 & -0.592 & -0.483 & 0.442 & 1.798 & -0.592 & -0.592 \\
\hline Dominica & 2.831 & -0.371 & -0.227 & 0.084 & -0.393 & -0.238 & -0.349 & -0.404 & -0.404 & -0.360 \\
\hline Dominican Republic & -1.127 & -1.211 & -0.939 & 0.342 & -0.687 & 0.559 & 0.627 & 0.418 & 1.977 & 0.041 \\
\hline El Salvador & 0.635 & -0.773 & -0.832 & 0.631 & -0.799 & -0.383 & -0.725 & 2.008 & 0.282 & 1.220 \\
\hline Equator & 0.634 & -0.774 & -0.830 & 0.631 & -0.800 & -0.383 & -0.726 & 2.008 & 0.282 & 1.220 \\
\hline French Guiana & -0.209 & -0.673 & -0.248 & 0.525 & -0.914 & -0.828 & 1.478 & -0.746 & 0.909 & 1.755 \\
\hline Granada & 1.205 & -0.765 & -0.301 & 0.823 & 1.524 & -0.156 & -0.591 & 1.495 & -0.852 & -0.736 \\
\hline Guadalupe & -0.001 & 0.151 & -0.786 & 0.786 & -0.580 & -0.484 & -0.786 & -0.318 & 1.711 & 1.877 \\
\hline Guatemala & -0.876 & -1.046 & -0.081 & 0.494 & -1.081 & 1.823 & -0.573 & 1.172 & 0.691 & 0.466 \\
\hline Guyana & -0.642 & -0.642 & 1.526 & 0.642 & -0.642 & -0.385 & 0.171 & 2.096 & -0.195 & -0.642 \\
\hline Haiti & -0.316 & -0.316 & -0.316 & 0.316 & -0.316 & -0.316 & -0.316 & 2.846 & -0.316 & -0.316 \\
\hline Honduras & 1.199 & -1.515 & -0.693 & 0.554 & 0.026 & -0.461 & -1.029 & 1.764 & -0.128 & 0.283 \\
\hline Jamaica & 2.118 & -0.459 & -0.502 & 1.651 & -0.490 & -0.489 & -0.469 & -0.398 & -0.451 & -0.511 \\
\hline Martinique & -0.238 & -0.306 & -0.455 & 0.600 & -0.429 & -0.503 & 2.778 & -0.335 & -0.030 & 0.119 \\
\hline Mexico & 0.979 & 0.977 & 1.962 & 0.230 & -0.278 & -1.004 & -0.780 & -0.570 & -0.850 & -0.665 \\
\hline Montserrat & 2.826 & -0.257 & -0.385 & 0.385 & -0.385 & 0.000 & -0.343 & -0.343 & -0.343 & -0.385 \\
\hline Nicaragua & 2.065 & -0.610 & -0.556 & 1.144 & 0.748 & 0.125 & -0.722 & -0.688 & -0.609 & -0.896 \\
\hline Panama & 1.322 & -0.626 & 0.943 & 1.081 & 1.066 & -1.051 & 0.003 & -0.713 & -1.057 & -0.969 \\
\hline Paraguay & -0.385 & -0.385 & -0.385 & 0.239 & 2.658 & -0.380 & -0.151 & -0.368 & -0.364 & -0.385 \\
\hline Peru & -0.527 & 0.012 & -0.730 & 0.784 & -0.848 & -0.122 & 2.506 & 0.377 & -0.394 & 0.510 \\
\hline Porto Rico & 0.170 & -0.269 & 0.269 & 2.672 & -0.190 & -0.788 & -0.134 & -0.659 & -0.484 & -0.588 \\
\hline St.Kitts & -0.702 & -0.702 & -0.702 & 0.702 & -0.702 & -0.702 & 1.471 & -0.214 & -0.653 & -0.604 \\
\hline Santa Lucia & 0.039 & 0.186 & -0.411 & 0.535 & -0.513 & -0.546 & 2.743 & -0.051 & -0.490 & -0.422 \\
\hline San Vicente & 1.837 & 1.444 & -0.721 & 0.263 & -0.663 & -0.698 & -0.721 & 0.691 & -0.721 & -0.710 \\
\hline Suriname & -0.830 & 0.058 & -1.507 & 1.321 & 0.106 & 1.113 & 0.279 & 1.196 & -0.987 & -0.747 \\
\hline Trinidad and Tobago & -1.090 & 0.937 & -0.829 & 0.461 & -0.563 & -0.121 & -0.023 & 2.186 & 0.002 & -0.960 \\
\hline Turks and Caicos Islands & -2.121 & -2.121 & -2.121 & 2.121 & -2.121 & -2.121 & -2.121 & 0.707 & -0.707 & -2.121 \\
\hline Venezuela & -0.085 & -1.283 & -0.010 & 0.191 & -0.373 & -0.665 & 2.556 & 0.195 & -0.359 & -0.167 \\
\hline
\end{tabular}



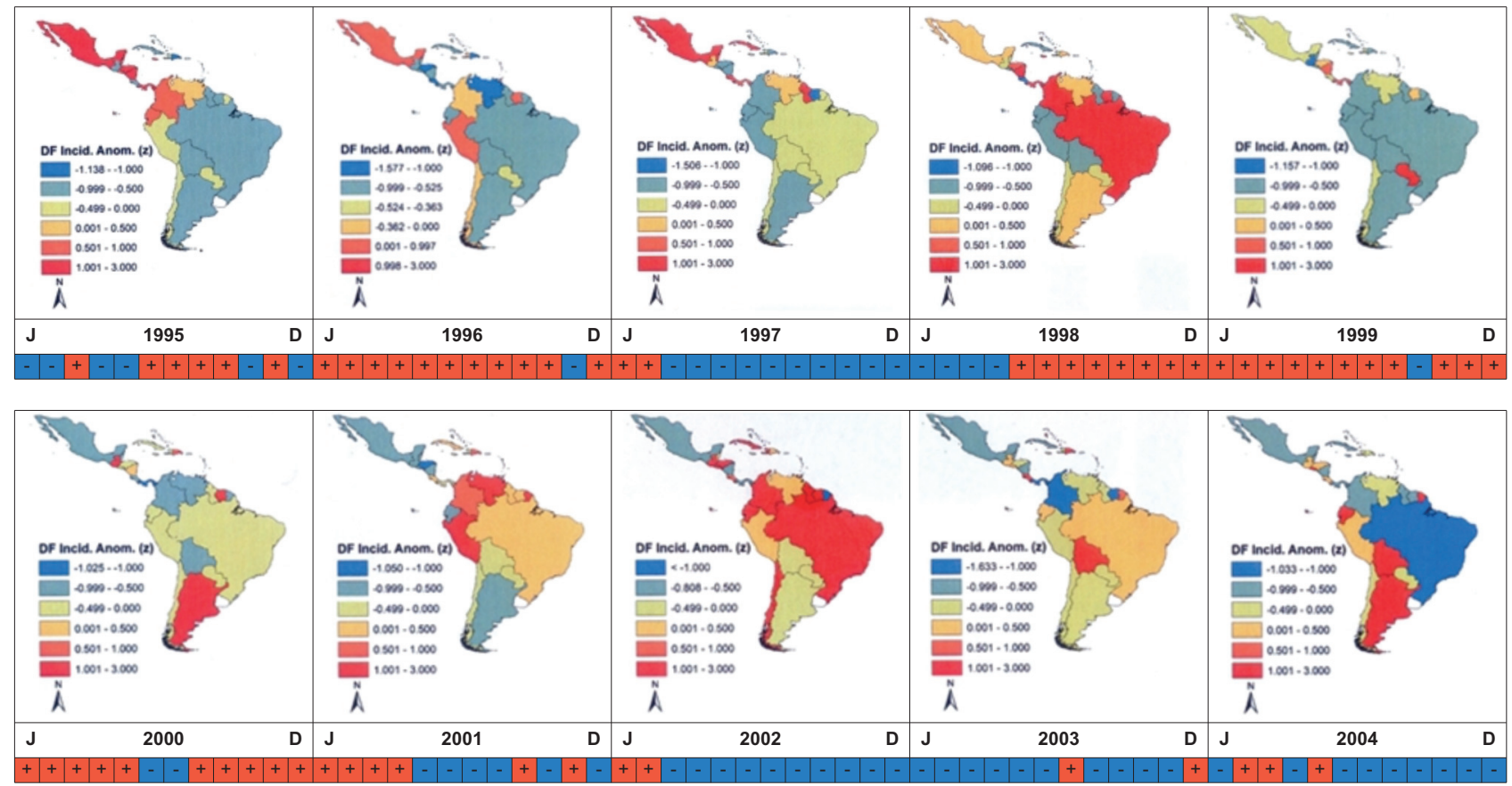

Fig. 4. Time sequence of the annual incidence of DF between 1995 and 2004. Positive anomalies of DF incidence are represented by reddish coulours and the negative anomalies in greenish colours. The squares in the legend below each map represent the months of the year, January $(\mathrm{J})$ to December $(\mathrm{D})$. Red squares corresponding to months with positive SOI values (La Niña effects) and blue squares corresponding to months with negative SOI values (El Niño effects). The incidences shown are based on $\mathrm{z}$ values.
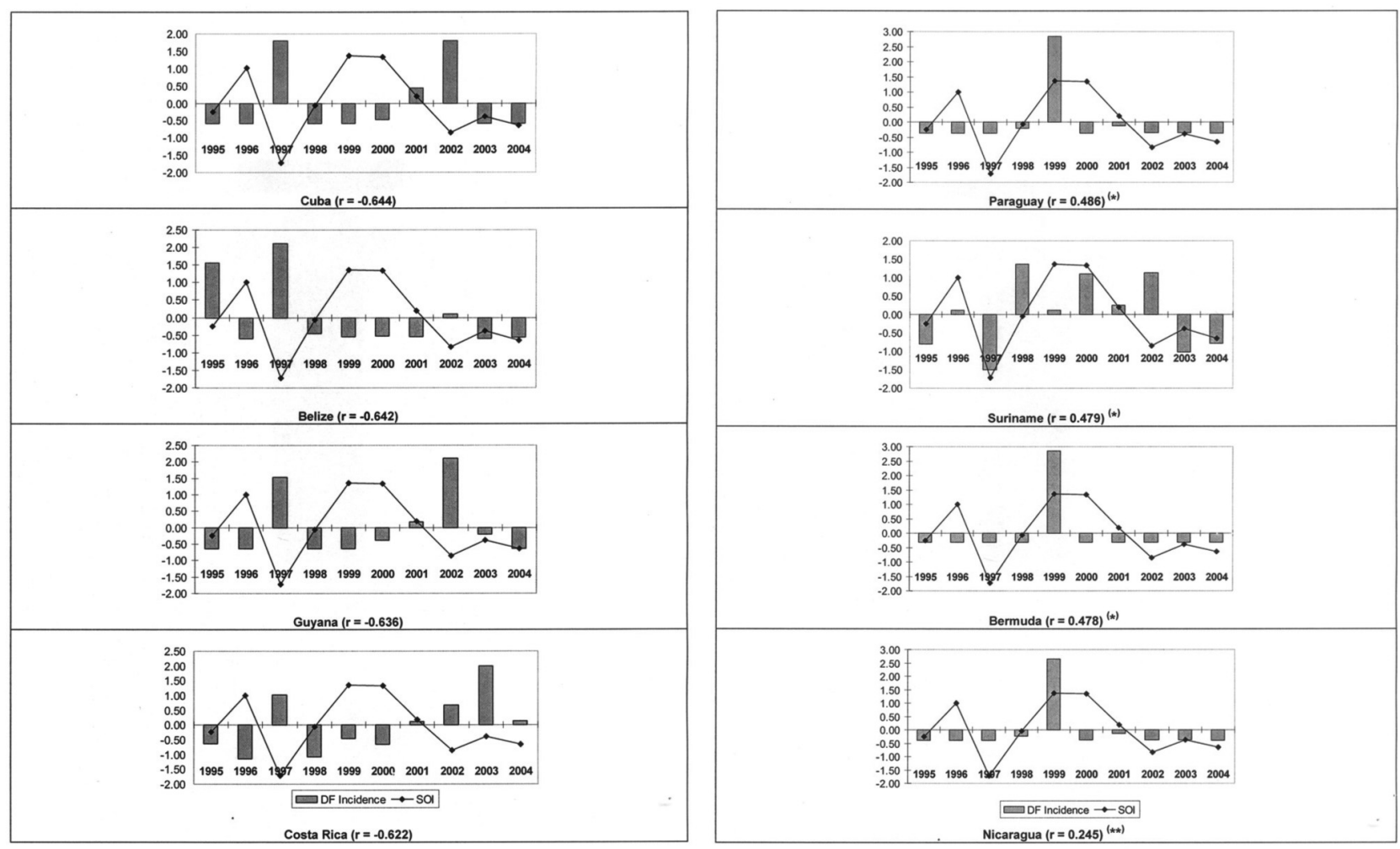

Fig. 5. Standardised annual DF incidence and SOI anomalies from selected countries of the Americas. Left: all countries showed negative associations; right: all countries showed negative associations that were statistically significant at P-value $=0.025$. Right: all countries showed negative associations varying between P-value $=0.10^{(*)}$ and $\mathrm{P}$-value $=0.25^{(* *)}$. 


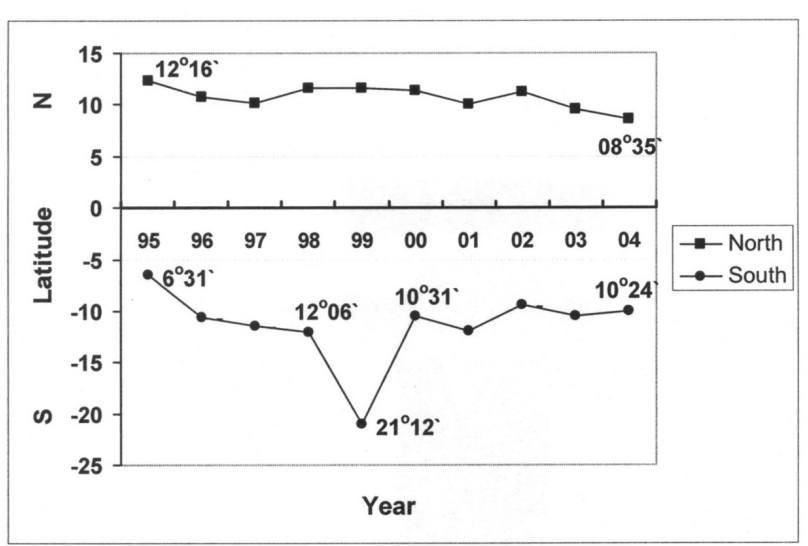

Fig. 6. Evolution of spatial weighted mean centre of DF incidence from 1995 to 2004 .

mainly in 1997, 2003 and 2004 (El Niño event years) and positive SOI and positive DF incidence deviations in 2000 (La Niña event year).

The evolution of spatial weighted mean centre of annual DF incidence, by hemisphere, is shown in Fig. 6. In the northern hemisphere the spatial weighted mean centre of DF incidence moved slightly southward passing from $W A I_{1995}=12^{\circ} 16^{\prime} \mathrm{N}$ to $W A I_{2004}=8^{\circ} 35^{\prime} \mathrm{N}$, while the $W A I_{y}$ showed a different variation in the southern hemisphere. From 1995 to

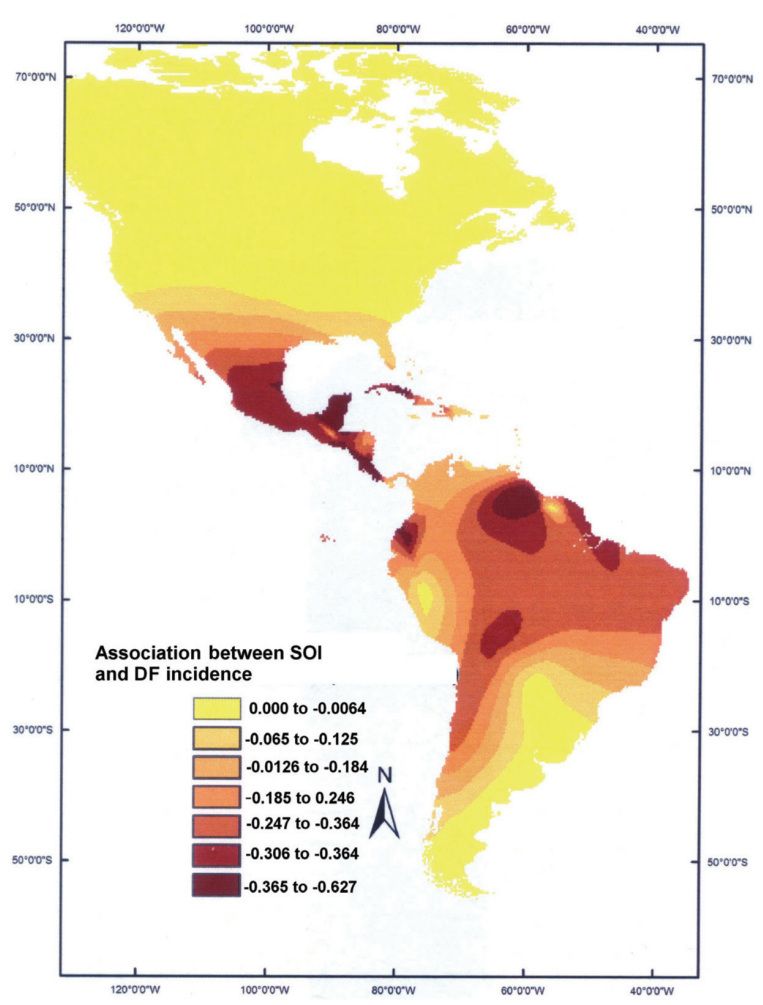

Fig. 7. Interpolated surface map of the associations between SOI and the DF annual incidence by country 1995-2004.
1998, a latitudinal expansion to the south $\left(W^{\prime} I_{1995}=06^{\circ} 31^{\prime} \mathrm{S}\right.$ to $\left.\mathrm{WAI}_{1998}=12^{\circ} 16^{\prime} \mathrm{S}\right)$ occurred. In 1999, the spatial weighted mean centre reached the maximum southern position at $W A I_{1999}=21^{\circ} 12^{\prime} \mathrm{S}$. In general, the spatial weighted mean centre of the DF incidence tended to move south in both hemispheres, but the expansion was more intense in the southern hemisphere, particularly in 1999.

Fig. 7 shows the spatial variation of SOI- $A I_{y}$ association based on $r$-value interpolation that visualises that the influence of ENSO on dengue fever was greater in countries located in Central America, Mexico and some of the northern Caribbean islands. The results show that the association between SOI and the annual DF incidence seems be more intense in the extreme north of South America, in some Andean regions, in the northwest and along the central Pacific coast and in northern Brazil. The DF-SOI association decrease quickly toward southern and northern high latitudes of the Americas.

\section{Discussion}

The southward expansion of the spatial weighted mean centre tendency observed in our research has been confirmed by recent DF outbreaks registered in Bolivia, the northern provinces of Argentina and in the Buenos Aires metropolitan area (Guzman and Istúriz, 2010). While DF has a pronounced circulation in most Caribbean countries, no viral activity was detected in Cuba from 1982 to 1996 (González et al., 2005), perhaps due to its political and economical isolation. However, in 1997 - a strong El Niño year - a positive deviation of the DF incidence in Cuba was noted confirming a possible positive ENSO influence.

Extreme weather events associated with ENSO, such as storms and tornados, occur with great intensity in the Caribbean region. These events may have influenced vector-borne disease outbreaks, DF in particular, in Guatemala, Belize and Nicaragua (Moreno, 2006). The high annual DF incidence values in the Caribbean may also be explained by the great number of discarded tires and water containers disposed with garbage and in many of the islands as this contributes strongly to the growth and Aedes larvae and spread of the vector (Amarakoon et al., 2008). It has been observed that the most infected Caribbean countries in the 1980-2001 time series were Trinidad, Tobago, Barbados, Jamaica and Porto Rico (CampionePiccardo et al., 2003; Depradine and Lovell, 2004; Amarakoon et al., 2008).

It is possible that all four serotypes were around in 
the Caribbean and Central American countries during the study period, thus contributing to the higher DF incidence these years. The mobility of people among Caribbean islands is another factor that no doubt has also contributed to the rapid geographical dispersion of DF serotypes in that region after 1981 (Carrington et al., 2005). In Mexico, the four serotypes were introduced after 1981 and the greater epidemic of 1995 2004 period occurred in 1997. The association of the following factors influenced the intensity of these outbreaks there: people living in slums; the practice of keeping water in containers for use in the dry season; no diary garbage collection; and the climatic factors. Hurtado-Diáz et al. (2007) claim that that the rise of the sea surface temperature is also associated with the increase of DF cases in Mexican counties located along the Mexico Gulf based on a regression coefficient of $r=0.51$ between the sea temperature and the number of weekly reported DF cases in state of Vera Cruz. While dry conditions persist during winter in northern South America, USA's southwest, the Yucatán Peninsula and Cuba in El Niño years, moist conditions associated with the northern Pacific Ocean occurs.

Corroborating our research, a study carried out by Gagnon et al. (2001) confirms the dependence between ENSO and DF cases in Suriname and French Guiana. The waves of DF epidemics that occurred in Brazil from 1994 to 2002 spread to almost the whole country with all four serotypes (Siqueira et al., 2005). In 2002, a strong El Niño year, $89.6 \%$ of Brazilian counties registered DF cases. Based on 2007-2010 data, Stewart-Ibarra and Lowe (2013) found that the ENSO has a strong influence on anomalies with regard to minimum temperature and precipitation in Ecuador, influencing the seasonal Ae. aegypti population dynamics.

\section{Conclusions}

The influence of ENSO on DF incidence and increase of the number of cases is particularly significant in Central America and Caribbean countries. This influence decreases rapidly with increasing of latitudes, mainly in South America. The southward, spatial dispersion of DF is particularly evident in the strongest El Niño years with DF also reaching countries located in the Andean region and at higher latitudes areas of continent. Although the climatic effects of ENSO reach continental scales, its influence on dengue epidemics depends on local environmental, demographical, social and economical particularities.
Therefore, the planning of public health interventions aimed combating the dengue epidemics should consider the socioeconomical vulnerability of each region of the country compared to the ENSO intensity in the same year.

\section{Acknowledgements}

The funding for this research was provided by a grant from São Paulo Research Foundation (FAPESP), São Paulo, Brazil.

\section{References}

Amarakoon D, Chen A, Rawlins S, Chadee DD, Taylor M, Stennett R, 2008. Dengue epidemics in the Caribbean-temperature indices to gauge the potential for onset of dengue. Mitig Adapt Strat Glob Chan 13, 341-357.

Australian Bureau of Meteorology, 2007. SST anomalies. Avaiable at: www.bom.gov.au/climate/enso/indices.shtml (accessed on December 2006).

Campione-Piccardo J, Ruben M, Vaughan H, Morris-Glasgow $\mathrm{V}, 2003$. Dengue viruses in the Caribbean: twenty years of dengue virus isolates from the Caribbean Epidemiology Centre. West Indian Med J 52, 191-198.

Carrington CV, Foster JE, Pybus OG, Bennett SN, Holmes EC, 2005. Invasion and maintenance of dengue virus type 2 and type 4 in the Americas. J Virol 79, 14680-14687.

Cazales B, Chavez M, McMichael AJ, Hales S, 2005. Nonstationary influence of El Niño on the synchronous dengue epidemics in Thailand. PLoS Med 2, 313-318.

Chadee DD, Shivnauth B, Rawlins SC, Chen AA, 2007. Climate, mosquito indices and epidemiology of dengue fever in Trinidad (2002-2006). Ann Trop Med Parasitol 101, 69-77. Changnon SA, 2000. El Niño 1997-1998: the climate event of the century. Oxford: Oxford University Press.

Chen A, Taylor MA, 2002. Investigating the link between early season Caribbean rainfalls and the El Niño +1 year. Int J Climatol 22, 87-106.

Cliff AD, Haggett P, 1988. Atlas of disease distributions: analytical approaches to epidemiological data. London: Blackwell UK.

Curto de Casas SI, Carcavallo RU, 1995. Climate change and vector-borne diseases distribution. Soc Sci Med 40, 1437 1440.

Delgado-Petrocelli L, Córdova K, Camardiel A, Aguilar VH, Hernández D, Ramos S, 2012. Analysis of the El Niño/La Niña-southern oscillation variability and malaria in the Estado Sucre, Venezuela. Geospat Health 6, S51-S57.

Depradine CA, Lovell EH, 2004. Climatological variables and the incidence of dengue fever in Barbados. Int $\mathrm{J}$ Environ Health Res 14, 429-441.

Epstein PR, Sharp D, 1993. Medicine in a warmer world. 
Lancet 342, 1000-1004.

ESRI, 2011. ArcGIS desktop: release, 2010. Environmental Systems Research Institute, Redlands, USA.

Gagnon AS, Bush ABG, Smoyer-Tomic KE, 2001. Dengue epidemics and the El Niño southern oscillation. Clim Res 19, 35 43.

González D, Castro OE, Kourí G, Perez J, Martinez E, Vazquez S, Rosario D, Cancio R, Guzman MG, 2005. Classical dengue hemorrhagic fever resulting from two-dengue infection spaced 20 years or more apart: Havana, dengue 3 epidemic, 20012002. Int J Infect Dis 9, 280-285.

Guzman A, Istúriz RE, 2010. Update on the global spread of dengue. Int J Antimicrob Agents 365, 540-542.

Hales S, Weinstein P, Souares Y, Woodward A, 1999. El Niño and the dynamics of vector-borne disease transmission. Environ Health Perspect 107, 99-102.

Hu W, Clements A, Willians G, Tong S, 2010. Dengue fever and El Niño southern oscillation in Queensland, Australia: a time series predictive model. Occup Environ Med 67, 307-311.

Hurtado-Diáz M, Riojas-Rodriguez H, Rothenberg SJ, GomezDantez H, Cifuentes E, 2007. Impact of climate variability on the incidence of dengue in México. Trop Med Int Health 12, 1327-1337.

Kiska DL, 2000. Global climate change: an infectious disease perspective. Clin Micro Newsletter 22, 81-86.

Manabe S, Stoufer RJ, 1993. Century scale effects of increased atmospheric $\mathrm{CO}_{2}$ on the ocean-atmosphere system. Nature $364,215-218$.
Moreno AR, 2006. Climate change and human health in Latin America: drivers, effects and policies. Reg Environ Change 6, 157-164.

NASA, 1999. What is El Niño. Available at: http://earthobservatory.nasa.gov/Features/EINino (accessed on October 2014).

Nicholls N, 1993. El Niño-southern oscillation and vectorborne diseases. Lancet 342, 1284-1285.

NOAA, 2014. National climatic center. South Oscillation Index, calculation of SOI. Available at: http://www.ncdc.noaa.gov /teleconnections/enso/indicators/soi.php\#soi-calculation (accessed on October 2014).

PAHO, 2007. Number of reported cases of dengue and dengue hemorrhagic fever. Available at: http://www.paho.org/English /sha/coredata/tabulator/newTabulator.htm (accessed on December 2009).

Siqueira JB, Martelli CMT, Coelho GE, Simplício ACR, Hatch DL, 2005. Dengue and dengue hemorrhagic fever, Brazil, 1981-2002. Emerg Infect Dis 11, 48-53.

Stewart-Ibarra AM, Lowe R, 2013. Climate and no-climate drives of dengue epidemics in southern coastal Equator. Am J Trop Med Hyg 88, 971-981.

Vitek CJ, Gutierrez JA, Dirrigl Jr. FJ, 2014. Dengue vectors, human activity and dengue virus transmission potential in the Lower Rio Grande Valley, Texas, United States. J Med Entomol 51, 1019-1028.

Wilder-Smith A, Gubler DJ, 2008. Geographic expansion of dengue: the impact of international travel. Med Clin North Am 92, 1377-1390. 